\title{
A Dynamic Model of Corporate Acquisitions*
}

\author{
Sandra Betton \\ Department of Finance \\ John Molson School of Business \\ Concordia University \\ 1455 de Maisonneuve Blvd. W. \\ Montréal, Québec \\ Canada H3G 1M8 \\ (514) 848-2783 \\ betton@vax2.concordia.ca
}

\author{
Pablo Morán ${ }^{\dagger}$ \\ Departamento de Economía y Finanzas \\ Facultad de Ciencias Empresariales \\ Universidad de Talca \\ Campus Lircay, Avda. Lircay s/n \\ Casilla 721, Talca \\ Chile \\ (514) 488-8317 \\ pmoran@vax2.concordia.ca
}

First Draft: August, 2002

This Version: January, 2003

\begin{abstract}
Using a game-theoretic real option approach, this paper presents a model of corporate acquisitions. We incorporate imperfect information about synergy gains, strategic interaction among competing bidders, and between the successful bidder and the target firm. Assuming the absence of managerial motives, the model is able to explain some empirical regularities that have only been explained under the agency and hubris hypotheses. Undervaluation, asymmetric distribution of gains, and divestitures are a natural output in our model. This theoretical model suggests that controlling for industry characteristics is an important element in empirical research.
\end{abstract}

JEL classification: G13, G34

Keywords: Acquisitions, Divestitures, Real Options, Timing Game.

${ }^{*}$ We thank Khaled Soufani and Cristián Troncoso for valuable comments and suggestions. All remaining errors are our own.

${ }^{\dagger}$ Graduate student at the John Molson School of Business, Concordia University. Morán thanks financial support from Universidad de Talca. 


\title{
A Dynamic Model of Corporate Acquisitions
}

\begin{abstract}
Using a game-theoretic real option approach, this paper presents a model of corporate acquisitions. We incorporate imperfect information about synergy gains, strategic interaction among competing bidders, and between the successful bidder and the target firm. Assuming the absence of managerial motives, the model is able to explain some empirical regularities that have only been explained under the agency and hubris hypotheses. Undervaluation, asymmetric distribution of gains, and divestitures are a natural output in our model. This theoretical model suggests that controlling for industry characteristics is an important element in empirical research.
\end{abstract}

JEL classification: G13, G34

Keywords: Acquisitions, Divestitures, Real Options, Timing Game.

The strategy literature recognizes that organizational capabilities or competencies can be a source of competitive advantage. As such, these capabilities are valuable and potentially transferable across products and industries. The starting point of our interest in applying the lessons from the real options literature to corporate acquisitions rests on the fact that in spite of all these years of empirical and theoretical research, there are still some issues that are unclear.

Evidence based on stock price reaction at the announcement dates strongly indicates that, on average, acquisitions are expected to create wealth ${ }^{1}$. This literature also shows that while bidders earn on average zero or negative abnormal returns during acquisition announcements, targets obtain positive excess returns [Jensen and Ruback (1983); Jarrell, Brickley and Netter (1988); and Andrade, Mitchell and Stafford (2001)]. On one hand, the managerial hubris hypothesis proposed by Roll (1986) predicts that acquisition announcements should have a zero combined abnormal return, as acquisitions would be only a transfer of wealth from bidder's shareholders to target's shareholders. The free cash flow hypothesis proposed by Jensen (1986) predicts, on the other hand, that the combined abnormal return should be negative as managers, instead of paying out the excess cash, use it to invest in negative net present value projects. Perhaps these two hypotheses have a great deal of importance in explaining some corporate failures, but the evidence indicating that transfers of control generate a combined positive abnormal return is clearly against their predictions.

\footnotetext{
${ }^{1}$ In this paper we differentiate expectation of and actual wealth creation. Long run event studies might be clouded with the bad model problem, and also with implementation issues in the post-acquisition integration process. Thus, our presumption is that short term event studies are able to capture the best forecast of wealth creation conditional on the information available at the announcement date.
} 
Divestitures $^{2}$ are also events that on average have positive combined abnormal returns [Alexander, Benson and Kampmeyer (1984); Jain (1985); Hite, Owers and Rogers (1987); and Mulherin and Boone (2000)]. This finding is interpreted in most of the literature as evidence that acquisitions and especially diversifying ones destroy value. Even though this interpretation is plausible, it is not clear why divesting firms wait long periods before divesting ${ }^{3}$. If this decision is made under the pressure of the market for corporate control, it is still not clear why bidders delay the offer for the undervalued assets. Following the Marshallian view of investments, bidders should make an offer for the undervalued assets as soon as the Net Present Value of the acquisition is equal to zero. The fact that we observe positive abnormal returns during announcements indicates that these decisions are made later than suggested by the Marshallian view ${ }^{4}$.

A finding that challenges the agency and hubris hypotheses of acquisitions is that acquisitions and divestitures occur in waves and with a marked industry clustering [Mitchell and Mulherin (1996)]. It is still an open question why managers, pursuing their own objectives, would tacitly agree to acquire at the same time. If this is due to informational cascades, there is no theory to explain what triggers the first acquisition. According to Weston (2002), the fact that restructuring activity occurs in waves and with industry clustering is evidence that firms respond efficiently to changes in the underlying political, financial, cultural and economic environment, which would be consistent with economic motives.

In this paper, we treat acquisition strategies as a mechanism that allows firms to exploit the aforementioned organizational capabilities. Starting from the observation that acquisitions and divestitures are two sides of the same coin, and from the assumption that managers always act in the best interest of shareholders, the first issue we address is the determination of the distribution of gains derived from corporate transfers of control. The second issue we address in the model is the effect of strategic interactions between target and bidder. We extend the current theoretical literature dealing with dynamic models of acquisitions [Lambrecht (2001) and Morellec (2002)] in several respects. Smit (2001) emphasizes the importance of strategic interactions in corporate acquisitions as firms rarely have monopoly rights over the acquisition

\footnotetext{
${ }^{2}$ In the present setting, we understand divestitures as any divisive action such as sell-offs, spin-offs or equity carve-outs

${ }^{3}$ Denis et al (1997) find evidence indicating that parent firms suffer a significant decrease in value for 3 years prior the divestiture. Kaplan and Weisback (1992) show that there is a considerable time lag between the acquisition and the divestiture. The median value for this time lag in their sample ranges from 15 years in 1971 to 4.5 years in 1982, showing a decreasing trend and a median for the period of 7 years.

${ }^{4}$ Even though asymmetric information together with the observability problem might add to explain part of these delays, it is difficult to argue that this is the only source of such a long delays. A potential explanation offered by Haynes et al $(2000,2003)$ is that poor corporate governance is responsible for this low speed of adjustment.
} 
of a given target (shared options). In addition, he highlights the importance of implementation uncertainty involved in acquisitions. To incorporate these features, we introduce strategic interaction among bidders as well as imperfect information about the synergy gains derived from the acquisition. This last feature gives rise to another notable feature of our model: the divestiture option.

Absent managerial motives, our model predicts that the distribution of gains is asymmetric between bidder and target. Even when the bidder has a comparative advantage in managing the target's resources, the target is able to extract most of this gain as a premium. This asymmetry is more pronounced when firms acquire rapidly growing and volatile firms. Competition among bidders force them to acquire at a non-optimal time and thus reduces their CARs at the announcement date. Interestingly, competition does not erode target's premium and thus it increases even more the asymmetric distribution of gains. The combined wealth effect depends on the timing of the acquisition, and this timing depends on the inertia induced by agents' optimal decisions. In our model, the highest combined excess return during acquisition or divestiture announcements should be observed in industries with high growth and high volatility, and when the buyer faces no competition in the contest.

Acquisitions and divestitures should occur in a rising market. Industry shocks might generate an acquisition wave when this shock takes firms into their acquisition regions. The model predicts that, ceteris paribus, industries with higher long term growth, lower volatility, an active or more liquid market for corporate assets, and with higher expected activity in the market for corporate control are more likely to experience acquisitions and divestitures. The model suggests, thus, that controlling for industry characteristics in empirical research is important.

The paper proceeds as follows. In the next section the model is developed. Our main interest in this section is to characterize the industry where acquisitions take place, to describe the environment within which agents make their decisions and finally to obtain the equilibrium strategies of all players. Section 2 is devoted to a brief discussion of some empirical regularities from our model's perspective. Section 3 concludes.

\section{The Model}

\subsection{Industry Characterization}

We assume that firms are price takers in their respective industries. Initially each firm posses one plant which has an optimal production scale of one unit of output. There are neither operating costs nor fixed costs of production. Firms are all equity financed ${ }^{5}$. All firms are risk

\footnotetext{
${ }^{5}$ The last two assumptions allow us to eliminate operating options (temporarily close or shut down the firm), and the problem of endogenous bankruptcy and under-investment respectively.
} 
neutral and discount their cash flows at the conditional risk free rate $r$. Time is continuous and indexed by $t \in[0, \infty)$. Acquisitions will take place in industry $i$ and for this industry the output price will fluctuate over time so as to clear the market according to the following function:

$$
P_{i}(t)=X_{i}(t) D[Q(t)] \quad \text { with } P_{i} \geq 0
$$

Where $Q$ is the quantity supplied at time $t^{6}, D($.$) corresponds to the deterministic part$ of the inverse demand function, which is assumed differentiable with $D^{\prime}(Q)<0$, and $X(t)$ represents external random shocks in demand. We assume that $X(t)$ follows a law of motion given by:

$$
d X=X \mu d t+X \sigma d W
$$

With $W$ being a one-dimensional standard Brownian motion with constant parameters $\mu$ and $\sigma$, and defined on a filtered probability space $\left(\Omega, \mathcal{F},\left(\mathcal{F}_{t}\right)_{t \geq 0}, \mathbb{P}\right)$. As an additional condition to ensure convergency in the value of firms, we impose $r>\mu$, where $\delta=r-\mu>0$ is the shortfall rate.

Using (2) and applying Itô's lemma to (1), the process followed by the equilibrium price in industry $i$ is given by $^{7}$ :

$$
d P_{i}(t)=\mu P_{i}(t) d t+\sigma P_{i}(t) d W+\frac{D^{\prime}[Q(t)]}{D[Q(t)]} P_{i}(t) d Q
$$

It has been shown [Dixit (1992)] that sunk costs of installment of new plants $(I)$, and uncertainty generate an area optimal inertia in the entry process of new firms in an industry. Following standard results in real options [Dixit and Pindyck (1994)], we can show that the point of entry of an idle firm ${ }^{8}$ will be given by:

$$
P^{e}=\left(\frac{\beta}{\beta-1}\right) I \delta \quad \delta=r-\mu>0
$$

Where $\beta>1$ is the positive solution to the fundamental quadratic:

$$
\frac{1}{2} \sigma^{2} \beta(\beta-1)+(r-\delta) \beta-r=0
$$

It is clear that free entry of new firms (new plants) in the industry will stop the growth in the price process at any time the price reach a level $P^{e}(d Q(t)>0)$; the price process will have

\footnotetext{
${ }^{6}$ Note that $Q$ also corresponds to the number of plants in the industry.

${ }^{7}$ Note that $d Q$ does not include a second order term because it is assumed of finite variation.

${ }^{8}$ This point of entry is the same no matter whether the firm has rational expectations or static expectations about the price process, see Leahy(1993)
} 
an upper reflecting barrier at $P^{e}$. Under our current setup, the value of an active firm in the industry will be given by:

$$
V_{t}(P)=\frac{P_{t}}{\delta}+E\left(P_{t}\right)
$$

Where the first term represents the firm value assuming no entry, and $E\left(P_{t}\right)$ corresponds to a negative amount accounting for the value lost due to the entry of new firms, see Dixit and Pindyck (1994).

In our model, firms cannot own more than one plant because they lack the ability to manage a bigger firm. However, there will be some firms endowed with organizational capabilities that allow them to operate more than one physical plant with efficiency gains. For tractability, we will assume that acquisitions of plants occur at a price far below $P^{e}$. This implies that there is no physical installment of new plants in the industry for the range of prices that makes acquisitions feasible ${ }^{9}$. Further, this assumption allows us to consider $E\left(P_{t}\right)$ as negligible.

Thus, the price process observed by endowed firms when making their acquisition decisions will be independent of $Q$, and will be given by:

$$
d P_{i}(t)=\mu P_{i}(t) d t+\sigma P_{i}(t) d W
$$

Thus far we have used the term plant in order to make the industry characterization easier, but clearly our setup can be generalized to acquisition of assets, business units, and firms in any industry. Indeed, in what follows we shall refer to acquisitions as any transaction that involves the complete transfer of ownership (and control) of assets, business units or firms from the target firm to the bidder firm ${ }^{10}$.

\subsection{Description of the Acquisition Game}

In our model bidders will be those firms with internal capabilities (growth options). We assume that these organizational capabilities are firm-specific or a non-tradable asset. Thus, rents generated accrue entirely to shareholders. Targets will be those firms without these capabilities, but that represent a good expected match for the bidder's organizational capabilities. In the present setting, we assume the existence of one target firm that is an expected compatible match for two bidders. The target firm belongs to industry $i$. The bidders may or may not be initially part of this industry, but if they acquire the target they will be competing in industry $i^{11}$.

As the synergy gains the bidder derives from acquiring a target represent the consolidation of resources of both bidder and target, we assume that bidders face imperfect information

\footnotetext{
${ }^{9}$ Without this assumption we would never observe acquisitions in industry $i$.

${ }^{10}$ Our model thus can be considered as more representative of cash offers and asset sales.

${ }^{11}$ We have to remark that acquisitions involve only the transfer of ownership. The number of plants in our hypothetical industry remains fixed as the current price level is not high enough for rational agents to install new plants.
} 
about the true synergy gains even though they have some clear idea (prior beliefs) about the distribution function of synergy gains. Thus, along with the economic uncertainty given by the price process, firms face implementation uncertainty. We need to emphasize that contrary to the economic uncertainty, which is resolved as time passes, the implementation uncertainty is only resolved when bidders actually acquire.

We assume that bidders have to incur a fixed sunk cost to carry out the acquisition given by $A$. Bidders also have the option to divest the acquired unit in case it results in a failed acquisition. Failed acquisitions ${ }^{12}$ in the context of our model are those in which the bidder's capabilities do not match ex-post with the target resources. In our setting, failures are not a consequence of agency problems or managerial hubris. Clearly, the market value of an ex-post failed acquisition will be lower than its potential under standard management ${ }^{13}$, and therefore, there is potential for a mutually beneficial transaction and efficiency improvements. If the acquisition is successful, the acquirer will never divest and will be able to keep the derived rent forever ${ }^{14}$.

We assume that the negotiation process for any acquisition is a dynamic game where the target sets his reservation premium first and then the bidder chooses the timing of the acquisition. As we have two bidders with the potential ability to increase the productivity of the target's resources, we assume that, in case of failure, the first acquirer has the option to sell the failed acquisition to the second bidder. If the second bidder fails, he has the option to divest and sell the business unit to a bidder with standard ability, but with certainty about the value of the business unit in his hands. We allow bidders to compete (if it is profitable to do so) for the target during any bidding process. The game among bidders is played simultaneously and we allow the first bidder to arise endogenously.

The market value of the bidders and the target will be given by:

$$
\begin{array}{ll}
V_{m}^{B}\left(P_{t}\right)=V^{B}\left(P_{t}\right)+F\left(P_{t}\right) & \text { for bidders } \\
V_{m}^{T}\left(P_{t}\right)=V^{T}\left(P_{t}\right)+F(\Psi) & \text { for target }
\end{array}
$$

Where $V^{j}\left(P_{t}\right)$ for $j=[T, B]$ is the market value of assets in place, $F\left(P_{t}\right)$ denotes a compound option of acquisition/divestiture held by the bidder, and $F(\Psi)$ denotes the present value of the acquisition premium held by the target. Hereafter, we will use only the option values $F($.$) s as$ players' payoffs since under our assumptions both components of the market value are additive.

\footnotetext{
${ }^{12} \mathrm{We}$ assume that a failed acquisition does not erode the value of the bidder's pre-existing assets (no externalities between different business units)

${ }^{13}$ We shall refer to standard management or standard ability as the level of ability held by any firm without these special organizational capabilities.

${ }^{14}$ The assumption of no divestiture in case of sucessful acquisition is made for simplicity. Competition or changes in the environment can erode and finally eliminate current synergy gains. In principle, our model can accommodate sudden death (Poison process) or depreciation (exponential decay) in the synergy gains.
} 
We denote the first bidder as bidder $\theta$ and the second bidder as bidder $\lambda$. Any management team with standard ability will be denoted as bidder $n$.

As failure by the first bidder might have positive informational externalities for the second bidder, we assume that there is learning between them (negative correlation). This means that the expected synergy gains of the second bidder conditional on the failure of the first bidder is higher than his unconditional expected synergy gains. In addition, we assume that these games are played in a setting with perfectly symmetric information among players. Even though this is not important for our modelling, we will assume, for simplicity, that external agents (the market) do not know about the deal until the announcement of the acquisition; the moment when the bidder exercises his option to acquire.

Summarizing, the timing of the game is as follows. Starting in the first stage, nature moves first and defines the state (successful or unsuccessful). The true state of nature is unknown for players until the actual acquisition. The target plays second and determines his reservation premium. Bidders move third and define their acquisitions strategies in a simultaneous game. Once the acquisition by the first bidder (bidder $\theta$ ) is consummated, all players learn the true state of nature. If the acquisition is successful the game ends. If the acquisition fails, we start the second stage. Nature moves again and defines the state. In this stage, bidder $\theta$ is willing to divest the just acquired firm, which is undervalued, and therefore he becomes the second stage target who negotiates a deal with bidder $\lambda$. If this second acquisition is successful the game ends. If the second acquisition fails we start the third and last stage. In this stage the bidder $\lambda$ is willing to divest and will negotiate the divestiture with any of the $n$ management teams with standard ability in industry $i$. As bidder $n$ has certainty about the value of the business unit for him, there is no chance for a failed acquisition and therefore the game ends.

Without loss of generality, we assume that the beliefs about synergy gains are given by the joint discrete distribution in Table 1.

\begin{tabular}{|rr|rrr|}
\hline & & & Bidder 2 & \\
& & $\lambda_{1}$ & $\lambda_{2}$ & $\mathbb{P}_{\theta}$ \\
\hline \multirow{3}{*}{ Bidder 1 } & $\theta_{1}$ & $\mathbb{P}(\mathrm{S}, \mathrm{S})$ & $\mathbb{P}(\mathrm{S}, \mathrm{U})$ & $\mathbb{P}_{\theta}(\mathrm{S})$ \\
& $\theta_{2}$ & $\mathbb{P}(\mathrm{U}, \mathrm{S})$ & $\mathbb{P}(\mathrm{U}, \mathrm{U})$ & $\mathbb{P}_{\theta}(\mathrm{U})$ \\
& $\mathbb{P}_{\lambda}$ & $\mathbb{P}_{\lambda}(\mathrm{S})$ & $\mathbb{P}_{\lambda}(\mathrm{U})$ & 1 \\
\hline
\end{tabular}

Table 1: Joint Probability Distribution of Synergy Gains

In table 1 , synergy gains for bidders are represented by the factors $\theta$ and $\lambda$, which multiply the current market value of the just acquired business unit, with $\theta_{1}>1, \theta_{2}<1, \lambda_{1}>1$ and $\lambda_{2}<1$. A realization $\theta_{1}$ or $\lambda_{1}$ during the acquisition implies a good ex-post match between bidder's capabilities and target's resources. Realizations $\theta_{2}$ and $\lambda_{2}$ represent bad 
ex-post marriages. $S$ and $U$ denotes successful and unsuccessful, $\mathbb{P}(A, B)$ denotes the joint probability of event $A$ and event $B$, and $\mathbb{P}_{\theta}$ and $\mathbb{P}_{\lambda}$ denote the marginal probability distributions of bidder $\theta$ and bidder $\lambda$ respectively. This distribution is common knowledge for all players.

Finally we assume the two bidders with ability are identical and have positive expected synergy gains:

$$
\begin{aligned}
\mathbb{E}_{t}(\theta) & =\mathbb{E}_{t}(\lambda)>1 \quad \text { for } t<\text { acquisition time. } \\
\mathbb{E}_{t}\left(\theta / \lambda_{2}\right) & =\mathbb{E}_{t}\left(\lambda / \theta_{2}\right)>\mathbb{E}_{t}(\theta)=\mathbb{E}_{t}(\lambda) \quad \text { due to learning. }
\end{aligned}
$$

Having completed the description of the game, in the next section we present formally the players' payoffs and find their equilibrium strategies.

\subsection{Equilibrium Strategies}

Prior to the any acquisition, the action set of targets is $\mathbb{A}=\{$ Accept, Reject $\}$. Under our setup, Accept will always be a dominant strategy for targets as long as bidders are able to pay a positive premium. As targets will not have ownership participation in the firm after the acquisition, their strategy and payoff will not depend on the true state of nature. Given the target's reservation premium, the action set of bidders corresponds to $\mathbb{A}=\{$ Acquire, Wait . If the acquisition is a success, the action set for bidders is $\mathbb{A}=\{$ Donothing $\}$. If the acquisition is a failure, the action set for bidder is $\mathbb{A}=\{$ Divest, Do not Divest $\}$. Given a failure, the dominant strategy for bidders is always Divest.

The equilibrium exercise strategies for bidders are derived as the solution of a timing game. We have to notice that the filtration generated by the price process coincides with that of the noise process $\left.W_{t}\right|_{t \geq 0}$ :

$$
\mathcal{F}_{t}^{W}=\sigma\left\{W_{\tau} / \tau \leq t\right\}=\sigma\left\{P_{\tau} / \tau \leq t\right\}=\mathcal{F}_{t}^{P}
$$

Thus, the information structure of the model is based exclusively on observations of the price process (4) at time $t$. Therefore, the exercise strategies for bidders will be Markov strategies corresponding, for player $p \in\{\theta, \lambda, n\}$, to a mapping $T_{p}: t \in[0, \infty) \rightarrow A_{p}$, that indicates when to acquire the target. Given that the strategies are Markov, the proper concept of equilibrium is the Markovian Nash equilibrium.

The structure of payoffs at the acquisition time is very similar in our three stages. For example, in the first stage the payoffs for bidder and target are respectively given by:

$$
\begin{aligned}
& F_{1}\left(P_{1}\right)=V\left(P_{1}\right)\left[E(\theta)-\left(1+\Psi_{1}\right)\right]-A+\mathbb{P}_{\theta}(U) F_{2}\left(\Psi_{2}\right) \\
& F_{1}\left(\Psi_{1}\right)=\Psi_{1} V\left(P_{1}\right)
\end{aligned}
$$


Where $P_{1}$ represents the exercise price of bidder $\theta$ (first bidder), $V\left(P_{1}\right)$ corresponds to the target's market value at the exercise price, $F_{2}\left(\Psi_{2}\right)$ represents the divestiture option held by bidder $\theta$ conditional on his failure, and $\Psi_{1}$ represents the target's reservation premium in stage 1. As is customary in dynamic games, we solve the game by folding back sub-games until the beginning of the game.

\subsubsection{Third Stage}

When arriving at stage three, all players know that bidder $\theta$ and bidder $\lambda$ failed. Given the poor match between bidders' capabilities and the target's resources, all players know that the the target's market value is $\lambda_{2} \theta_{2} V\left(P_{t}\right)$ and therefore is undervalued in relation to the standard $V\left(P_{t}\right)$. In this stage we have $n$ bidders of type $n$ and one target currently owned by firm $\lambda$.

The target's maximization problem consists of maximizing the present value of his premium:

$$
F_{3}\left(\Psi_{3}\right)=\sup _{\Psi_{3} \in[0,1]} \Psi_{3} \lambda_{2} \theta_{2} V\left(\Psi_{3}\right)\left(\frac{P_{t}}{P_{3}}\right)^{\beta}
$$

Where $V\left(\Psi_{3}\right)$ is the bidder $n$ 's reaction function, $\left(\frac{P_{t}}{P_{3}}\right)^{\beta}$ is the discount factor under the probability measure $\mathbb{P}$, and $P_{3}$ is the optimal trigger price of bidder $n$.

The bidder's maximization problem is given by the maximization of his acquisition option:

$$
F_{3}\left(P_{3}\right)=\sup _{P_{3} \in \mathbb{R}+} B\left(P_{3}\right) P_{t}^{\beta}
$$

Where $\mathrm{B}$ is chosen as to maximize the value of the option, and $\beta>1$ is the positive root of (3). At the optimal exercise price two conditions must be met:

$$
\begin{aligned}
B P_{3}^{\beta} & =V\left(P_{3}\right)\left[1-\lambda_{2} \theta_{2}\left(1+\Psi_{3}\right)\right]-A \quad \text { (value matching) } \\
A & =V\left(P_{3}\right)\left[1-\lambda_{2} \theta_{2}\left(1+\Psi_{3}\right)\right] \quad \text { (competition) }
\end{aligned}
$$

Substituting (8) into (7), we see that $B=0$. Thus the option value of bidder $n$ has zero value; there is no value of waiting and thus he exercises the option as soon as the traditional net present value is zero. This is a direct result of bidder $n$ fearing pre-emption from any of the other $n-1$ bidders with equal ability. Then from condition (8) we know that the reaction function of bidder $n$ is given by:

$$
P_{3}=\left(\frac{A \delta}{1-\lambda_{2} \theta_{2}\left(1+\Psi_{3}\right)}\right)
$$

It is clear from (9) that if the target sets a premium too high, he will have to wait longer to realize this premium ${ }^{15}$. Thus the target faces a trade off between a higher premium more

\footnotetext{
${ }^{15}$ Observe that $\frac{d P_{3}}{d \Psi_{3}}>0$
} 
heavily discounted and a lower premium which is less discounted. Using (9) to solve the target's problem (5), we obtain:

$$
\Psi_{3}=\frac{1}{\beta}\left(\frac{1-\lambda_{2} \theta_{2}}{\lambda_{2} \theta_{2}}\right)
$$

Replacing the optimal premium (10) in (9) we obtain the exercise price of bidder $n$ :

$$
P_{3}=\left(\frac{\beta}{\beta-1}\right)\left(\frac{A \delta}{1-\lambda_{2} \theta_{2}}\right)
$$

Thus the optimal stopping time for the bidder $n$ is given by:

$$
T_{3}=\inf \left[t \geq 0: P_{t} \geq\left(\frac{\beta}{\beta-1}\right)\left(\frac{A \delta}{1-\lambda_{2} \theta_{2}}\right)\right]
$$

The pair of strategies (10) and (12) constitutes the Nash Equilibrium for this sub-game.

The optimal strategy for the firm divesting the business unit is thus to demand as premium a fraction $\frac{1}{\beta}$ of the relative undervaluation $\frac{1-\lambda_{2} \theta_{2}}{\lambda_{2} \theta_{2}}$. A standard result from the real options literature is that $\frac{d \beta}{d \sigma}$ and $\frac{d \beta}{d \mu}$ are negative [see Dixit and Pindyck (1994)]. It means that, ceteris paribus, a higher growth and volatility in the business unit's industry implies a higher seller's reservation premium, $\Psi_{3}$. From (9) we see that a higher premium means a higher acquisition trigger price. Therefore, divestitures are expected to be faster in industries with low volatility and growth. We see that competition in this scenario with standard-ability bidders, forces firms to acquire earlier than the optimal time.

Even though there are efficiency improvements for the economy, the acquiring firm in this game obtains zero expected gain no matter the industry characteristics. Substituting (10) into (8), we see that the expected gain accruing to the bidder $\frac{1-\lambda_{2} \theta_{2}}{\lambda_{2} \theta_{2}} \frac{\beta-1}{\beta}$ is just enough to cover the acquisition sunk costs $A$. Therefore, even though the business unit is undervalued, in equilibrium, firms with standard ability should earn a normal economic profit during acquisitions.

Two deeper issues are worthwhile discussing here. First, it is clear that in this fully competitive scenario for bidders, targets could accelerate divestitures most by choosing a zero premium. The natural question that arises is why are targets willing to induce inertia in the divestiture decision by requiring a positive premium?. The simple answer is that this is in the best interest of shareholders. Dixit, Pindyck and Sødal (1999) show that in the case of geometric Brownian motions, the parameter $\beta$ is the elasticity of the discount factor in relation to the optimal threshold. Thus and even though the acquisition for bidder $\lambda$ was a failure, he maximizes the value of his divestiture option at the point where an additional dollar of premium is just equal to the marginal cost imposed by the discount factor. In few words, by choosing a markup equal to (10) the target minimizes the value lost in a failed acquisition.

Second, is there any possibility that the market reacts negatively to this acquisition?; is there a possibility that the bidder gets a negative stock price reaction during the third stage 
acquisition?. Grenadier (2002) analyzes the effects of competition on the likelihood of investment values falling below their initial cost. Through simulation exercises, he shows that this possibility increases dramatically when investors cannot exercise their real options optimally due to competition. It is hardly arguable that the market has better information about the potential gains derived from the acquisition than the insiders, but at the exercise time the market knows that this bidder exercised when the expected net present value is zero. In our model, all information about the evolution of the output price is summarized by the current price and no agent can have better information. In reality, however, it is perfectly arguable that the market at the acquisition announcement is able to form a better forecast about the future evolution of the industry or the economy in general. Therefore, a sufficient condition for negative stock price reactions for this bidder is that the market forecasts a downturn in output prices, which will render the acquisition a negative net present value investment.

\subsubsection{Second Stage}

When players arrive to this stage, it is common knowledge that bidder $\theta$ failed and is therefore willing to divest the business unit. Bidder $\lambda$ and bidder $n$ know that the market value of the firm is lower than that they could achieve. All players know that bidder $\lambda$ is the one with the highest potential gains. As before, the target and bidder maximization problems are given respectively by:

$$
\begin{aligned}
& F_{2}\left(\Psi_{2}\right)=\sup _{\Psi_{2} \in[0,1]} \Psi_{2} \theta_{2} V\left(\Psi_{2}\right)\left(\frac{P_{t}}{P_{2}}\right)^{\beta} \\
& F_{2}\left(P_{2}\right)=\sup _{P_{2} \in \mathbb{R}+} B\left(P_{2}\right) P_{t}^{\beta}
\end{aligned}
$$

Even though bidder $n$ is already active as a potential bidder, for the moment we will assume that bidder $\lambda$ faces no pre-emption threat. Later we will show that bidder $n$ does not participate in this contest. At the optimal exercise price $P_{2}$ by bidder $\lambda$, the value of his acquisition option must meet the value matching and smooth pasting conditions:

$$
\begin{aligned}
B P_{2}^{\beta} & =V\left(P_{2}\right)\left[\mathbb{E}_{t}\left(\lambda / \theta_{2}\right)-\theta_{2}\left(1+\Psi_{2}\right)\right]-A+\mathbb{P}(U, U) F_{3}\left(\Psi_{3}\right) \\
\beta B P_{2}^{\beta-1} & =\frac{1}{\delta}\left[\mathbb{E}_{t}\left(\lambda / \theta_{2}\right)-\theta_{2}\left(1+\Psi_{2}\right)\right]
\end{aligned}
$$

Using conditions (15) and (16), the bidder's reaction function is:

$$
P_{2}=\left(\frac{\beta}{\beta-1}\right)\left(\frac{\delta\left(A-\mathbb{P}(U, U) F_{3}\left(\Psi_{3}\right)\right)}{\mathbb{E}_{t}\left(\lambda / \theta_{2}\right)-\theta_{2}\left(1+\Psi_{2}\right)}\right)
$$

Using (17) and (13) we find that the target will demand a premium:

$$
\Psi_{2}=\frac{1}{\beta}\left(\frac{\mathbb{E}_{t}\left(\lambda / \theta_{2}\right)-\theta_{2}}{\theta_{2}}\right)
$$


Replacing the optimal premium (18) in the reaction function of the bidder (17), we obtain the acquisition trigger price:

$$
P_{2}=\left(\frac{\beta}{\beta-1}\right)^{2}\left(\frac{\delta\left(A-\mathbb{P}(U, U) F_{3}\left(\Psi_{3}\right)\right)}{\mathbb{E}_{t}\left(\lambda / \theta_{2}\right)-\theta_{2}}\right)
$$

So far we have assumed that bidder $\lambda$ faces no threat of pre-emption by bidder $n$. As bidder $n$ obtains zero in the third stage, it is clear that he has the incentive to compete if he can obtain more than zero in this stage. Assuming that the target will set the premium according to the most efficient bidder, a necessary condition for competition is that the bidder $n$ has a positive premium:

$$
1-\theta_{2}\left(1+\Psi_{2}\right)>0 \Longrightarrow \beta>\frac{\mathbb{E}_{t}\left(\lambda / \theta_{2}\right)-\theta_{2}}{1-\theta_{2}}
$$

Even though condition (20) is a necessary condition for competition, it is not sufficient as the optimal trigger price (19) can be lower than that necessary for bidder $n$ to have zero profit. The zero profit price for bidder $n$ is given by:

$$
P_{2}^{n}=\left(\frac{\delta \beta A}{\beta\left(1-\theta_{2}\right)-\left(\mathbb{E}_{t}\left(\lambda / \theta_{2}\right)-\theta_{2}\right)}\right)
$$

For competition in the second stage, the sufficient condition is thus that $P_{2}^{n}<P_{2}$. To examine the behavior of this relation, we compare the ratio of the trigger prices:

$$
\frac{P_{2}}{P_{2}^{n}}=\left(\frac{A-\mathbb{P}(U, U) F_{3}\left(\Psi_{3}\right)}{A}\right)\left(\frac{\beta}{\beta-1}\right)^{2}\left(\frac{1-\theta_{2}}{\mathbb{E}_{t}\left(\lambda / \theta_{2}\right)-\theta_{2}}-\frac{1}{\beta}\right)
$$

The last term in (22) is just the inverse of the necessary condition given in (20) and therefore this must be positive for bidder $n$ to compete. The first and second terms are less than one, and greater than one respectively. To prove that $P_{2}$ is always less than $P_{2}^{n}$, we will analyze the range of $\beta \in\left(\frac{\mathbb{E}_{t}\left(\lambda / \theta_{2}\right)-\theta_{2}}{1-\theta_{2}}, \infty\right)$. It is easy to show that as $\beta$ tends to the inferior limit of the range, the ratio (22) tends to zero. This is because the trigger price (21) tends to infinity faster than the trigger price (19). The same analysis can be applied to the ratio (22) when $\beta$ tends to infinity. We see that in this case the second term tends to one while the other two remains less than one. In conclusion, the ratio (22) ranges from zero to a number less than one, and therefore $P_{2}<P_{2}^{n}$.

As Bidder $n$ does not participate in this contest, the optimal stopping time for bidder $\lambda$ is thus given by:

$$
T_{2}=\inf \left[t \geq 0: P_{t} \geq\left(\frac{\beta}{\beta-1}\right)^{2}\left(\frac{\delta\left(A-\mathbb{P}(U, U) F_{3}\left(\Psi_{3}\right)\right)}{\mathbb{E}_{t}\left(\lambda / \theta_{2}\right)-\theta_{2}}\right)\right]
$$

The premium set by the target in this scenario without threat of pre-emption for bidder $\lambda$, (18), is exactly the same as that demanded by the third stage target (10). The target 
thus asks for a premium assuming that the bidder will exercise optimally, and therefore, the characteristics of the bidding process do not affect target's excess return. What should ne noted here, however, is that competition, as we saw in the previous game, erodes bidder's excess return as he is forced to acquire non-optimally. Thus competition alters the relative distribution of gains between bidder and target.

From (19) we see that the divestiture option held by bidder $\lambda$ reduces the trigger price as it reduces the net sunk cost of acquisition. Clearly, the option to divest makes the acquisition less irreversible and thus the bidder will be less reluctant to acquire. This indicates, ceteris paribus, that industries with more liquid or more active market for corporate assets are more likely to experience acquisitions and divestitures. Furthermore, higher expected activity in the market for corporate control will also enhance the value of this divestiture option, accelerating acquisitions.

The absence of competition induces the bidder to acquire later as to maximize the value of the acquisition option. The total hysteresis effect is now composed of the effects induced by both bidder and target. This indicates that the combined excess return should be higher at announcement dates, ceteris paribus, when the bidder faces no competition and when the unit being divested is in a high growth and volatility industry.

It is interesting to analyze the behavior of bidder's excess return in this stage since here the bidder is able to maximize the value of his acquisition option. The option value is characterized as follows:

$$
F_{2}\left(P_{t}\right)= \begin{cases}\frac{A-\mathbb{P}(U, U) F_{3}\left(\Psi_{3}\right)}{\beta-1}\left(\frac{P_{t}}{P_{2}}\right)^{\beta}, & \text { for } P_{t}<P_{2} \\ V\left(\mathbb{E}_{t}\left(\lambda / \theta_{2}\right)-\theta_{2}\right) \frac{\beta-1}{\beta}-A+\mathbb{P}(U, U) F_{3}\left(\Psi_{3}\right), & \text { for } P_{t} \geq P_{2}\end{cases}
$$

Using the equation above and (18) we can see that the cumulative abnormal returns ${ }^{16}$ for target and bidder respectively at the announcement are given ${ }^{17}$ by:

$$
\begin{aligned}
C A R_{\text {Target }} & =\frac{1}{\beta}\left(\frac{\mathbb{E}_{t}\left(\lambda / \theta_{2}\right)-\theta_{2}}{\theta_{2}}\right)=\Psi_{2} \\
C A R_{\text {Bidder }} & =\frac{\beta-1}{\beta^{2}}\left(\frac{\mathbb{E}_{t}\left(\lambda / \theta_{2}\right)-\theta_{2}}{\theta_{2}}\right)
\end{aligned}
$$

We see that the target's cumulative abnormal return is a decreasing function of $\beta$ as $\frac{d C A R_{\text {target }}}{d \beta}<0$. This implies that target's CARs will be higher for acquisitions in more growing and volatile industries. Derivation of bidder's CAR indicates that this function has a global

\footnotetext{
${ }^{16}$ We assume that the cumulative abnormal return is identical to the net gain for players. It does not necessarily mean that we should observe these abnormal returns during acquisition announcements as the market can have already impounded some of the gain before the announcement.

${ }^{17}$ Both CARs are given in relation to the prior announcement target's value, $\theta_{2} V$.
} 
maximum at $\beta=2$, where the bidder obtains $25 \%$ of the expected increase in value. At $\beta$ $=2$, the target's CAR corresponds to $50 \%$ of the total expected gains. The remaining $25 \%$ is equivalent to the sunk costs of acquisition, $A$, less the divestiture option. The explanation for the behavior of the bidder's CAR is that for low levels of $\beta$, the target demands most of the expected gains as premium. On the other hand, for higher values of $\beta$ the bidder exercises sooner and even though the premium for the target is lower, the acquisition costs $A$ represents a greater portion of the expected increase in value. Finally it is observed from this game that even though the bidder is able to maximize the value of his acquisition option, he will never obtain more than the target does. The ratio of target's CAR to bidder's CAR corresponds to $\frac{\beta}{\beta-1}$, which starts from $+\infty$ when $\beta$ tends to 1 , and tends to 1 when $\beta$ tends to $+\infty$. Thus, conditional on the acquisition announcement, acquiring firms will obtain the lowest return relative to the target when the target is operating in a high growth and also a high volatility industry.

\subsubsection{First Stage}

At the beginning of the game all bidders are active in the market for corporate control. The target is in hands of a $n$ type firm, and therefore, the only two bidders with potential efficiency improvements are bidder $\theta$ and bidder $\lambda$. The target and bidder maximization problem are given respectively by:

$$
\begin{array}{ll}
F_{1}\left(\Psi_{1}\right)=\sup _{\Psi_{1} \in[0,1]} \Psi_{1} V\left(\Psi_{1}\right)\left(\frac{P_{t}}{P_{1}}\right)^{\beta} \\
F_{1}\left(P_{1}\right)=\sup _{P_{1} \in \mathbb{R}+} B\left(P_{1}\right) P_{t}^{\beta}
\end{array}
$$

Let us assume for the moment that bidder $\theta$ faces no competition. The value matching and smooth pasting conditions indicate that the the best response for bidder $\theta$ given the target's premium is:

$$
P_{1}^{M}=\left(\frac{\beta}{\beta-1}\right)\left(\frac{\delta\left(A-\mathbb{P}_{\theta}(U) F_{2}\left(\Psi_{2}\right)\right)}{\mathbb{E}_{t}(\theta)-\left(1+\Psi_{1}\right)}\right)
$$

Where $P_{1}^{M}$ denotes price assuming that the bidder has a monopolistic right over the acquisition. Given the bidder's reaction function (28), the target maximizes his payoff function (26) asking for a premium:

$$
\Psi_{1}=\frac{1}{\beta}\left(\frac{\mathbb{E}_{t}(\theta)-1}{1}\right)
$$

Again the target asks for a premium corresponding to $\frac{1}{\beta}$ of the total expected synergy gains $^{18}$. Replacing the target's premium in (28), we obtain the monopoly trigger price for bidder $\theta$ as:

\footnotetext{
${ }^{18}$ All the the previous discussion about the optimal inertia induced by the target applies here.
} 


$$
P_{1}^{M}=\left(\frac{\beta}{\beta-1}\right)^{2}\left(\frac{\delta\left(A-\mathbb{P}_{\theta}(U) F_{2}\left(\Psi_{2}\right)\right)}{\mathbb{E}_{t}(\theta)-1}\right)
$$

We impose $A-\mathbb{P}_{i}(U) F_{2}^{i}\left(\Psi_{2}\right) \geq 0$ to avoid arbitrage, and $A-\mathbb{P}_{i}(U) F_{2}^{i}\left(\Psi_{2}\right)>0$ to introduce irreversibility. If the leader's role were assigned exogenously, this price would the optimal. At this point we are interested in two results. First, given that we have a learning situation between the two bidders, it might be the case that one or both bidders have the incentive to wait and be the second bidder in case the first bidder fails. In the extreme case when both bidders prefer to wait and see, we would not observe acquisitions unless the target is willing to reduce the probability of failure to one or both bidders. Second, given that the leader arises endogenously, we must determine the equilibrium or the optimal strategy of both players.

For any bidder $i$, it will be optimal to compete in the first stage as long as he can get more now than in the second stage:

$$
F_{1}^{i}\left(P_{t}\right) \geq \mathbb{P}_{j}(U) F_{2}^{i}\left(P_{t}\right)
$$

This expression reflects the fact that the acquisition option for bidder $i$ in the second stage has value conditional on bidder $j$ 's failure. Further, the right hand side, $\mathbb{P}_{j}(U) F_{2}^{i}\left(P_{t}\right)$, can be interpreted as an additional opportunity cost of the first stage acquisition for bidder $i^{19}$. Hence, if the right hand side is always greater than the left hand side, bidder $i$ will prefer to be the second mover. Otherwise, he will prefer to compete in the first stage. At the break-even price, denoted by $P_{1}$, we must have:

$$
V\left(P_{1}\right)\left(\mathbb{E}_{t}(i)-1\right) \frac{\beta-1}{\beta}-A+\mathbb{P}_{i}(U) F_{2}^{i}\left(\Psi_{2}\right)=\mathbb{P}_{j}(U) F_{2}^{i}\left(P_{1}\right)
$$

The first term in the left hand side of (31) represents the net synergy value for bidder $i$, and results from subtracting the value premium for the target, $\frac{V\left(P_{1}\right)\left(\mathbb{E}_{t}(i)-1\right)}{\beta}$, from the total value of synergies, $V\left(P_{1}\right)\left(\mathbb{E}_{t}(i)-1\right)$. Given the assumption of symmetry between bidders, we know that $F_{2}^{i}\left(P_{1}\right)$ will be exercised at the same price no matter who is the successful bidder, and therefore $F_{2}^{i}\left(\Psi_{2}\right)$ and $F_{2}^{i}\left(P_{1}\right)$ are perfectly comparable without discounting. Further, the premium set by the target in this first stage will be the same for both bidders.

We have to realize that if $P_{1}$ were greater than $P_{1}^{M}$, player $i$ would prefer to acquire in the second stage. For competition in the first stage, we need $P_{1}<P_{1}^{M}$. In principle as both bidders are identical (symmetrical strategies), the equilibrium must be given by pre-emption or by a war of attrition depending on the strength of the first or second mover advantage respectively. Rearranging (31) and (30) conveniently and using our notation, we have:

\footnotetext{
${ }^{19}$ This additional opportunity cost might be given by a second chance as in this case, but it also can be interpreted as positive information spill-overs from the first bidder to subsequent bidders in the industry. Clearly, positive externalities from first movers to second movers such as a better estimate of expected synergy gains might impose an additional opportunity cost to the first bidder, inducing delay.
} 


$$
\begin{aligned}
V\left(P_{1}\right)\left(\mathbb{E}_{t}(\theta)-1\right) & =\left(\frac{\beta}{\beta-1}\right)\left[A-\mathbb{P}_{\theta}(U) F_{2}^{\theta}\left(\Psi_{2}\right)+\mathbb{P}_{\lambda}(U) F_{2}^{\theta}\left(P_{1}\right)\right] \\
V\left(P_{1}^{M}\right)\left(\mathbb{E}_{t}(\theta)-1\right) & =\left(\frac{\beta}{\beta-1}\right)^{2}\left[A-\mathbb{P}_{\theta}(U) F_{2}^{\theta}\left(\Psi_{2}\right)\right]
\end{aligned}
$$

From these equations we know that if the first one is greater (smaller) than the second one, then $P_{1}>P_{1}^{M}\left(P_{1}<P_{1}^{M}\right)$. It is observed that the strategy followed in the previous game of analyzing the limits of the ratio of the two prices for different limits of $\beta$ is not convenient here. In this case, $F_{2}^{\theta}\left(\Psi_{2}\right)$ and $F_{2}^{\theta}\left(P_{1}\right)$ are compound options that depend on $\beta$ through the optimal exercise price $P_{2}$. Thus, our strategy to analyze the behavior of the two prices will be done by construction.

Subtracting the second from the first equation and after some manipulation, we obtain:

$$
\left(P_{1}^{M}-P_{1}\right)\left(\frac{\mathbb{E}_{t}(\theta)-1}{\delta}\right)=\left(\frac{\beta}{\beta-1}\right)\left[\frac{A-\mathbb{P}_{\theta}(U) F_{2}^{\theta}\left(\Psi_{2}\right)}{\beta-1}-\mathbb{P}_{\lambda}(U) F_{2}^{\theta}\left(P_{1}\right)\right]
$$

The first factor in the right hand side of (32) is always greater than one by definition, and therefore, the sign of the difference is determined exclusively by the second factor in the right hand side. We also know that $A-\mathbb{P}_{\theta}(U) F_{2}^{\theta}\left(\Psi_{2}\right)$ is greater than zero by assumption ${ }^{20}$. It is easy to see that (32) has the unique root at $\beta=\frac{A-\mathbb{P}_{\theta}(U) F_{2}^{\theta}\left(\Psi_{2}\right)}{\mathbb{P}_{\lambda}(U) F_{2}^{\theta}\left(P_{1}\right)}+1$. We will call this expression $\beta^{U}$, which will denote the upper limit of $\beta$ that makes the sign change from positive to negative in (32). As we see here, $\beta^{U}$ is always greater than 1 , and therefore, there will always be a set of parameters consistent with $\beta>\beta^{U}$ or $\beta<\beta^{U}$ for a given game.

Interestingly, no matter what the actual value of $P_{1}^{M}$ is, both bidders will always exercise at $P_{1}$, where both will be indifferent between being the first or the second mover. However, the strategies for $\beta>\beta^{U}$ and $\beta<\beta^{U}$ are different. In the former case, we know that $P_{1}^{M}<P_{1}$, and therefore, both bidders will want to exercise later than optimal in the hope that the other player moves first. In this interesting case, the presence of a second potential bidder actually delays investment even further than optimal. The logic is as follows. When the price process reaches the level $P_{1}^{M}$ at time $t$, bidder $i$ will prefer to wait $t+d t$ for bidder $j$ to exercise. Bidder $j$ knows it and he will wait even longer for bidder $i$ to exercise until $t+2 d t$. The process follows until $P_{1}$, where the second mover advantage turns into a first mover advantage. On the other hand, for the case where $\beta<\beta^{U}$ we know that $P_{1}^{M}>P_{1}$, and thus both bidders will want to exercise earlier than optimal. It is clear that if bidder $i$ plans to exercise at $P_{1}^{M}$, bidder $j$ will try to exercise at $t-d t$. As bidder $i$ knows it, he will try to exercise at $t-2 d t$ and so on. Nevertheless, it should be noted that for a given acquisition, $\beta^{U}$ will be probably large as $\mathbb{P}_{\lambda}(U) F_{2}^{\theta}\left(P_{1}\right)$ is expected to be small in relation to the numerator. This makes in fact very

\footnotetext{
${ }^{20}$ This assumption was imposed because otherwise we would not have irreversibility in the acquisition.
} 
unlikely to have a situation in which $\beta>\beta^{U}$. It would observed only in acquisitions of targets in industries with very low growth and also low volatility. Thus, competition is probably the most likely outcome, but it is not the only possible one.

From this argument, we can deduce that the only trigger price consistent with equilibrium is $P_{1}$, at which both bidders are indifferent between being the first or the second bidder. As both bidders are symmetrical, there is always rent equalization in equilibrium. For the former case discussed above, we will have a war of attrition, and for the latter a preemption situation.

Formalizing the strategy for bidder $\theta$, we have:

$$
T_{1}=\inf \left[t \geq 0: P_{t} \geq\left(\frac{\beta}{\beta-1}\right) \frac{\delta\left[A-\mathbb{P}_{\theta}(U) F_{2}^{\theta}\left(\Psi_{2}\right)+\mathbb{P}_{\lambda}(U) F_{2}^{\theta}\left(P_{1}\right)\right]}{\mathbb{E}_{t}(\theta)-1}\right]
$$

From this strategy, we see that the divestiture option accelerates acquisition. Contrary to the conventional wisdom and our previous results in game three, the presence of a second bidder might actually delay the acquisition in relation to the optimal time. Our findings in the two previous games indicate that acquisitions will be less likely, ceteris paribus, in industries with high growth and volatility. This type of industries are, however, those for which the actual $\beta$ is more likely to be less than the measure we define as $\beta^{U}$ in this game. Thus, competition for high growth and volatility industries will probably accelerate acquisitions. On the other hand, industries with low growth and volatility are more likely to have $\beta>\beta^{U}$, and therefore, there will be some additional delay in relation to the optimal time in these industries when there is more than one potential bidder for the target.

The acquisition option in this case for bidder $\theta$ is represented as:

$$
F_{1}\left(P_{t}\right)= \begin{cases}\mathbb{P}_{\lambda}(U) F_{2}^{\theta}\left(P_{t}\right)\left(\frac{P_{t}}{P_{1}}\right)^{\beta}, & \text { for } P_{t}<P_{1} \\ V\left(\mathbb{E}_{t}(\theta)-1\right) \frac{\beta-1}{\beta}-A+\mathbb{P}_{\theta}(U) F_{2}^{\theta}\left(\Psi_{2}\right), & \text { for } P_{t} \geq P_{1} .\end{cases}
$$

The cumulative abnormal returns for the players in this stage are given by:

$$
\begin{aligned}
C A R_{\text {Target }} & =\frac{1}{\beta}\left(\mathbb{E}_{t}(\theta)-1\right)=\Psi_{1} \\
C A R_{\text {Bidder }} & =\frac{\mathbb{P}_{\theta}(U) F_{2}^{\lambda}\left(P_{1}\right)}{V\left(P_{1}\right)}
\end{aligned}
$$

Even though learning is not necessarily the only source of the second mover advantage for this game, we see that the higher the learning, the higher $F_{2}^{\lambda}\left(P_{1}\right)$, and therefore, the higher the bidder $\theta$ 's CAR at the announcement. By the same token, a higher unconditional probability of failure of bidder $\theta$ implies a higher CAR for bidder $\theta$. This result might appear counterintuitive, 
but this has a logical explanation. A higher probability of failure for bidder $\theta$ increases the exante payoff of the second bidder, and thus, increases the trigger price at which the acquisition option is exercised.

One important parameter that determines whether or not firms strategically over delay their acquisitions is $\beta^{U}=\frac{A-\mathbb{P}_{\theta}(U) F_{2}^{\theta}\left(\Psi_{2}\right)}{\mathbb{P}_{\lambda}(U) F_{2}^{\theta}\left(P_{1}\right)}+1$. An action that might actually accelerate acquisitions is an intervention by the target firm that could eventually reduce the probability of failure for one or both bidders. Reducing $\mathbb{P}_{\theta}(U)$ or $\mathbb{P}_{\lambda}(U)$ in $\beta^{U}$ will increase the value of $\beta^{U}$. This action by the target can turn an attrition situation into a preemptive game. Even though it may seem a reasonable strategy for the target in real life, in the model the target does not have an incentive to act in this way. All games we have studied show that the target sets a premium independent of the actual exercise trigger. As was mentioned in game one, this strategy allows the target to protect himself from the effect of discounting.

An important finding in this game and in the two previous games is that competition forces firms to exercise the acquisition options at a price different from the one that maximizes the value of the acquisition option. Hence, the model might rationalize strategic acquisitions or alliances. Even though there might not be synergy gains if bidder $\theta$ and bidder $\lambda$ merge for example, by doing so, they could exercise their acquisition option at its maximum value as they would face no competition. Thus far we have assumed non-cooperative behavior, but if we assume that bidders can agree on how to split the gains from the acquisition, both would be better off by forming a joint venture, strategic alliances or simply by merging as this would also allow them to improve the timing of exercise ${ }^{21}$.

A final remark that emerges from this game is that even though there is competition, an acquirer with higher-than-normal ability should experience positive excess returns during acquisitions. Competition amongst these bidders reduces but does not eliminates gains.

\section{Implications and Discussion of Empirical Literature}

In this section we analyze some stylized facts revealed in the empirical literature from the perspectives derived in our model. It is important to say at this point that agency and hubris are surely important issues in corporate governance. What we try to offer here is an alternative interpretation for some of the phenomena documented in the empirical literature.

According to our model, acquisitions and divestitures should occur in a rising market and should, on average, improve efficiency. This is consistent with evidence reported in Maksimovic and Phillips (2001). For the period 1974-1992, they find that on average $3.9 \%$ of the large manufacturing plants in the US change ownership, but they point out that this average has an

\footnotetext{
${ }^{21}$ It is not difficult to calculate the optimal trigger from the social point of view, but we only concentrate here on private benefits of acquisitions.
} 
intra-industry variability and also a pro cyclical time variation with an average of almost $7 \%$ during expansions. They find that asset sales are more likely when the economy is undergoing positive demand shocks, when the assets are less productive than their industry benchmark, when the selling division is less productive and when the selling firm has more productive divisions in other industries. They conclude that, in general, transactions in the market for assets result in productivity gains, and thus, facilitate the redeployment of assets from firms with a lower ability to firms with higher ability to exploit assets.

In our model, acquisitions and divestitures are modelled as an industry phenomenon. Mitchell and Mulherin (1996) report evidence for the 1980s that takeovers and restructuring activities cluster in industries that experience shocks of the greatest magnitude. They report that a few industries concentrate a high percentage of takeover activity. They also point out that this industry clustering is a characteristic of acquisitions during 1980s as these patterns are not observed in earlier periods. Andrade, Mitchell and Stafford (2001) argue that if each takeover wave is different in terms of industry composition, then unexpected industry shocks are probably the cause of the takeover activity. In our model the sunk costs of acquisitions must be understood as internal as well as external costs imposed by financing availability, regulations, etc. Thus, our model predicts that shocks reducing the cost of acquisitions could also induce restructuring activity.

Andrade, Mitchell and Stafford (2001) state that a challenge to the value creation hypothesis in mergers, in favor of the empire building hypothesis, is the fact that target's shareholders are able to obtain most of the gains even when there is no competition during the acquisition. A conclusion from our model is that even when the bidder is the owner of the intangible asset, the target is able to extract most of the synergistic gains. In our model the bidder actually never gets more than the target does. This phenomenon is not due to overpayment but due to the strategic interaction among agents. The model suggests that the distribution of gains between the bidder and the target are a function of fundamental industry characteristics, in particular the growth and volatility, and a function of how the deal is carried out (competition or not competition). Bradley, Desai and Kim (1988) find that bidder excess returns are higher for the 1960's than those of 1980's. They report that bidders obtain positive CARs in acquisitions with a single bidder and before the passage of the Williams Act. They conclude that competition in the market for corporate control reduces bidder's CARs. Our model is consistent with this explanation, but also adds another non-exclusive dimension. Acquisitions in the 1960's in relation to those in 1980's were probably more concentrated in lower growth and lower volatility industries. Thus we propose that a potential selection bias can help to explain the reduction in bidder's CARs over time.

Morck, Shleifer and Vishny (1990) find evidence that bidders get the lowest returns when buying growth and diversification. They interpret the evidence by arguing that managers 
buy growth for empire building purposes. Our model predicts exactly their evidence but the interpretation is very different. Conditional on acquisition, the target gets most of the synergy gains as a premium and the relative distribution of gains is even more asymmetric when the target is from a more growing industry. Fuller, Netter and Stegemoller (2002) find that target and bid characteristics are the main driving factor in bidder's CARs during 1990s. They note two interesting empirical issues related to our results. First, researchers have been unable to explain much of the variation in bidder's CARs. Second, they use a dummy variable to identify if target or bidder is an internet-related firm and state: "the theory is unclear on how the presence of an internet firms in a deal would affect the bidder returns". Our model offers a potential explanation for these issues.

Lang and Stulz (1994), and Berger and Ofek (1995) find that diversified firms trade at a discount relative to the sum of the market values of comparable single-segment firms. In our model, acquirers should trade at a discount if target's resources are not a good match for the acquirer's organizational capabilities ex-post. We have to emphasize that our model predicts this discount for diversifying acquisitions as well as for related acquisitions, but a reasonable conjecture is that the probability of match is higher when bidder and targets belong to the same industry. Campa and Kedia (2002) address the diversification discount from a different perspective. They point out that diversification is an endogenous decision and therefore previous studies suffer from the endogeneity problem. They propose that it is the discount that induces firms to diversify and not the other way around. Controlling for the selection bias induced by firm characteristics, they find that the diversification discount normally drops or sometimes even turns into a premium. Our model also suggests that endogeneity is an issue in corporate acquisitions as some industries are more prone to experience acquisitions and divestitures, in particular, industries with lower growth and volatility and industries where the divestiture option is more valuable ${ }^{22}$.

Mitchell and Lehn (1990) find evidence that firms making value decreasing acquisitions are more likely to become acquisition targets than those firms making value increasing acquisitions. They conclude that, consistent with the disciplinary role of the market for corporate control, one source of value in takeovers is to recoup some of the value lost in hands of the unsuccessful bidders. Kaplan and Weisbach (1992) in a study of large acquisitions during 1971-1982 find that by the end of 1989, acquirers had divested almost $44 \%$ of the target firms. From the divested units, they classify between $34 \%$ and $50 \%$ as unsuccessful or performance related. They also show evidence indicating that the market is able to recognize good deals at the announcement

\footnotetext{
${ }^{22}$ Schlingerann, Stulz and Walking (2002) find that conditional on the need to divest, the liquidity of the market for corporate assets is an important determinant in the decision of which asset to divest. In our model, liquidity enhances the value of the divestiture option.
} 
date $^{23}$. Lang, Poulsen and Stulz (1995) find that asset sales follow poor firm performance. John and Ofek (1995) find that the remaining assets of the firm improve performance after an asset sale that increases focus. In addition to the agency explanation in acquisition failures, our model proposes that managers can make mistakes, but as a consequence of imperfect information about the potential gains of the acquisition strategy rather than due to agency considerations ${ }^{24}$. The important issue in our model is that even though we can observe mistakes ex-post in corporate acquisitions, ex-ante they are a value maximizing strategy when firms have intangible assets potentially transferable to other products or industries. Thus long term poor performance post acquisition might not be necessarily due to managerial motives. In this respect, our model borrows insights from Matsusaka (2001), and Bernardo and Chowdhry (2002).

Evidence summarized in Mulherin and Boone (2000) indicates that divisional restructuring results in positive market reactions. Two hypotheses has been proposed to explain the combined abnormal returns during divestitures. The fit hypothesis predicts a higher combined stock price reaction when the buyer has a comparative advantage in managing the asset being sold. The focus hypothesis predicts higher returns when the asset being sold is not related to seller's core business. John and Ofek (1995) find evidence that both hypotheses have empirical support. The natural question that arises is why do firms wait so long to divest?. In theory, firms should divest as soon as the net present value is zero. One answer might be poor corporate governance. We propose that this abnormal return generated during divestitures are an explicit symptom of the well known hysteresis effect. The model predicts that the higher the hysteresis effect, the higher is the combined CAR during divestitures. John and Ofek (1995) also find that excess return to buyers is insignificantly different from zero and all gains accrue to the seller. They argue that this might be a consequence of competition, target-specific assets or simply overpayment. Our model predicts that, absent overpayment and target-specific assets, most gains accrue to the seller.

\section{Conclusions and Final Remarks}

The literature of real options has brought many lessons and new insights about how rational investment are carried out. Acquisitions and divestitures are important corporate events and one of the major corporate capital investments. In this paper we start with a very simple motivation, why do we observe abnormal returns during these events?. Understanding that acquisitions are latent investments, firms should, according to the marshalian view, invest as

\footnotetext{
${ }^{23}$ Our model does not explore how the market forms its expectations, but we pointed out that the possibility of negative abnormal returns for bidders might exist under a not restrictive assumption.

${ }^{24}$ This feature force firms to enter in a costly search. In this sense out model resembles real option models with time to build, but in this case firms do not have the option to default.
} 
soon as the net present value is zero. By the same token, firms should divest as soon as the net present value of the disinvestment is zero. Under these circumstances, we should observe no abnormal returns during announcements. One potential answer is that firms unexpectedly find good investments. What we argue here is that firms rationally wait until the optimal time to exercise their acquisition or divestiture options. This last feature would induce optimal inertia in takeovers and would be the cause of observed abnormal returns.

The model presented in this paper proposes some new insights about how acquisitions and divestitures might be affected by the optimal decision making of individuals under uncertainty and strategic interactions. The model presents a new set of testable hypotheses in relation to likelihood and timing of acquisitions and divestitures, and abnormal returns at the announcement dates. As discussed in the previous section, several empirical regularities found in the literature are natural outputs in our model. Most of these empirical regularities have only been interpreted through the eye of the agency and hubris theories without a real alternative hypothesis. The many still unexplored predictions in the model are clearly an interesting research area for future work.

Even though a model must be scrutinized based on its empirical support, it is perhaps necessary to justify at this point our modelling choice. First, dealing with stock offers call necessarily for the incorporation of asymmetric information and thus the adverse selection problem among bidder, target and outsiders. Thus, our model deals only with cash offers. Second, one important element left out is the free rider problem proposed by Grossman and Hart (1980). We believe that acquirers paying target's reservation premium mitigates to some extent this limitation and at the same time is a reasonable approximation to reality. Finally, most explanations about acquisition findings rest on the agency or managerial hubris theories. What we intended in our paper is to show a new perspective for the same problem. Thus, we voluntarily left out the potential moral hazard problem between shareholders and managers when the ownership is diffused. In this sense, our model by no mean is a substitute of agency and hubris hypotheses, but it can be considered as an alternative hypothesis. 


\section{References}

[1] Alexander, Gordon, George Benson, and Joan Kampmeyer, 1984, Investigating the Valuation Effects of Announcements of Voluntary Corporate Sell-offs. The Journal of Finance 39, 503-517.

[2] Andrade, Gregor, Mark Mitchell, and Erik Stafford, 2001, New Evidence and Perspectives on Mergers. Journal of Economic Perspectives 15, 103-120.

[3] Berger, Phillips, and Eli Ofek, 1995, Diversification's Effect On the Firm Value. Journal of Financial Economics 37, 39-65.

[4] Bernardo, Antonio and Bhagwan Chowdhry, 2002, Resources, Real Options, and Corporate Strategy. Journal of Financial Economics 63, 211-234.

[5] Bradley, Michael, Anand Desai, and E. Han Kim, 1988, Synergistic Gains from Corporate Acquisitions and Their Division Between the Stockholders of Target and Acquiring Firms. Journal of Financial Economics $21,3-40$.

[6] Campa, Jose M., and Simi Kedia, 2002, Explaining the Diversification Discount. The Journal of Finance 57, 1731-1762.

[7] Denis, D.J, D.K. Denis and A. Sarin, 1997, Agency Problems, Equity Ownership and Corporate Diversification. Journal of Finance 52, 135-160.

[8] Dixit, Avinash, 1992, Investment and Hysteresis. Journal of Economic Perspectives 6, 107-132.

[9] Dixit, Avinash, and Robert Pindyck, 1994, Investment Under Uncertainty. Princeton: Princeton University Press.

[10] Dixit, Avinash, Robert Pindyck, and Sigbjørn Sødal, 1999, A Markup Interpretation of Optimal Investment Rules. The Economic Journal 109, 179-189.

[11] Fuller, Kathleen, Jeffry Netter, and Mike Stegemoller, 2002, What Do returns to Acquiring Firms Tell Us? Evidence from Firms that Make Many Acquisitions. The Journal of Finance 57, 1763-1793.

[12] Grenadier, Steven, 2002. Option Exercise Games: An Application to the Equilibrium Investment Strategies of Firms, The Review of Financial Studies 15, 691-721.

[13] Grossman, Sanford and Oliver Hart, Takeover Bids, The Free Rider Problem, and The Theory of The Corporation. Bell Journal of Economics 11, 42-64.

[14] Haynes, Michelle, Steve Thompson, and Mike Wright, 2000, The Determinants of Corporate Divestment in the UK. International Journal of Industrial Organization 18, 1201-1222.

[15] Haynes, Michelle, Steve Thompson, and Mike Wright, 2003, The Determinants of Corporate Divestment: Evidence from a Panel of UK Firms. Journal of Economic Behavior $\& 3$ Organization, forthcomming.

[16] Hite, Gailen, James Owers, and Ronald Rogers, 1987, The Market of Interfirm Asset Sales: Partial Sell-offs and Total Liquidations. Journal of Financial Economics 18, 229-252.

[17] Jain, Prem, 1985, The Effects of Voluntary Sell-offs Announcements on The Shareholder Wealth. The Journal of Finance 40, 209-224.

[18] Jarrel, Gregg, James Brickley, and Jeffry Netter, 1988, The Market for Corporate Control: The Empirical Evidence since 1980. Journal of Economic Perspectives 2, 49-68. 
[19] Jensen, Michael, 1986, The Agency Cost of Free Cash Flow: Corporate Finance and Takeovers. American Economi Review 76, 323-329.

[20] Jensen, Michael and Richard Ruback, 1983, The Market for Corporate Control: The Scientific Evidence. Journal of Financial Economics 11, 5-50.

[21] John, Kose, and Eli Ofek, 1995, Asset Sales and the Increase in Focus. Journal of Financial Economics $37,105-126$.

[22] Kaplan, Steven and Michael Weisbach, 1992, The Success of Acquisitions: Evidence from Divestitures. The Journal of Finance 47, 107-138.

[23] Lambrecht, Bart, 2001, The Timing and Terms of Takeovers Under Uncertainty: A real Options Approach. Working Paper, University of Cambridge.

[24] Lang, Larry and René Stulz, 1994, Tobin's Q, Corporate Diversification and Firm Performance. Journal of Political Economy 102, 1248-1280.

[25] Lang, Larry, Annette Poulsen, and Rene Stulz, 1995, Asset Sales, Firms Performance and the Agency Costs of Managerial Discretion. Journal of Financial Economics 10, 767-804.

[26] Leahy, John, 1993, Investment in Competitive Equilibrium: The Optimality of Myopic Behavior. The Quarterly Journal of Economics November, 1105-1133.

[27] Maksimovic, Vojislav and Gordon Phillips, 2001, The Market for Corporate Assets: Who Engages in Mergers and Asset Sales and Are There Efficiency Gains?. The Journal of Finance 56, 2019-2065.

[28] Matsusaka, John, 2001, Corporate Diversification, Value Maximization, and Organizational Capabilities. Journal of Business 74, 409-431.

[29] Mitchell, Mark and Kenneth Lehn, 1990, Do bad Bidders become Good Targets?. Journal of Political Economy 98, 372-398.

[30] Mitchell, Mark and Harold Mulherin, 1996, The Impact of Industry Shocks on Takeover and Restructuring Activity. Journal of Financial Economics 41, 193-229.

[31] Mork, Randall, Andrei Shleifer, and Robert Vishny, 1990, Do Managerial Objectives Drive Bad Acquisitions?. The Journal of Finance 45, 31-48.

[32] Morellec, Erwan, 2002, The Dynamics of Merger and Acquisitions. Working Paper, University of Rochester.

[33] Mulherin, Harold, and Audra Boone, 2000, Comparing Acquisitions and Divestitures. Journal of Corporate Finance 6, 117-139.

[34] Roll, Richard, 1986, The Hubris Hypothesis of Corporate Takeovers. Journal of Business 59, 197-216.

[35] Smit Han T. J., 2001, Acquisitions Strategies as Option Games. Journal of Applied Corporate Finance 14, 79-89.

[36] Schlingemann, Frederik, Rene Stulz, and Ralph Walking, 2002, Divestitures and the Liquidity of the Market for Corporate Assets. Journal of Financial Economics 64, 117-144.

[37] Weston, Fred, 2002, Mergers and Acquisitions as Adjustment Processes. Journal of Industry, Competition and Trade 64, 117-144. 